\title{
MENENTUKAN POSISI PENGEBORAN UNTUK MENDAPATKAN AIR YANG BERKUALITAS DI JALAN TUNJUNG I DENPASAR BARAT DENGAN METODE GEOLISTRIK
}

\author{
I Kadek Suardika*, I Nengah Simpen ${ }^{1}$, I Wayan Redana² \\ ${ }^{1}$ Jurusan Fisika, Fakultas MIPAUniversitas Udayana, Kampus Bukit Jimbaran, Badung, Bali Indonesia \\ 80361. '2Jurusan Teknik Sipil, Fakultas Teknik Universitas Udayana, Kampus Bukit Jimbaran,Badung, \\ Bali Indonesia 80361 \\ *Email:dikaudayana15@gmail.com
}

\begin{abstract}
Abstrak
Telah dilakukan investigasi tetang posisi titik pengeboran untuk mendapatkan air bersih di Jalan Tunjung 1 Denpasar Barat. Investigasi dilakukan dengan metode geolistrik dengan menggunakan konfigurasi Wenner. Data hasil pengukuran diolah dengan mengunakan Software Res2dev. Dari hasil pengolahan data resistivitasnya diperoleh bahwa posisi terbaik untuk mendapatkan air yang berkualitas adalah pada posisi $8^{\circ} 33^{\prime} 43,76^{\prime \prime}$ LS dan $115^{\circ} 21^{\prime} 00,06$ "BT. Posisi aquifer terletak pada kedalaman 16,25 meter. Hasil uji laboratoriium untuk beberapa parameter yang berhubungan dengan kualitas air memperlihatkan nilai yang memnuhi ambang baku mutu menurut ketentuan Peraturan Gubernur Bali No. 8 Tahun 2007.
\end{abstract}

Keywords: Resistivitas Geolistrik, Konfigurasi Wenner, Pumping Test, Kualitas Air.

\begin{abstract}
Investigation has been conducted on drilling point position to get clean water at Jalan Tunjung 1 Denpasar Barat. The investigation was carried out by geoelectric method using the Wenner configuration. The measurement data is processed by using Res2dev Software. From the resistivity data processing results obtained that the best position to get quality water is at position $8^{\circ} 33^{\prime} 43,76$ "LS and $115^{\circ} 21^{\prime} 00,06^{\prime \prime}$ BT. The position of the aquifer lies at a depth of 16.25 meters. Laboratory test results for several parameters relating to water quality show values that meet the quality standard threshold in accordance with the provisions of Bali's Governor Regulation no. 8 Year 2007.
\end{abstract}

Keywords: Geoelectric Resistivity, Wenner Configuration, Pumping Test, Water Quality

\section{PENDAHULUAN}

Air yang berkualitas merupakan salah satu komponen penting dalam kehidupan sehari-hari. Untuk mendapatkan air bersih yang berkualitas sesuai standar kesehatan sangatlah sulit. Karena banyak faktor penyebab atau masalah yang dihadapi dalam mencari sumber air yang tepat. Sumur berkualitas baik yaitu debit air yang tetap dan mengandung parameter sesuai ketentuan Peraturan Gubernur Bali No.8 Tahun 2007 tentang baku mutu air.

\section{TINJAUAN PUSTAKA}

\subsection{Pengertian Geolistrik}

Geolistrik adalah suatu metode dalam geofisika yang mempelajari sifat aliran listrik di dalam bumi dan cara mendeteksinya di permukaan. Pendeteksian ini meliputi pengukuran beda potensial, arus dan elektromagnetik yang terjadi akibat pengijeksian arus ke dalam bumi [1]. 


\subsection{Konfigurasi Wenner}

Pada konfigurasi Wenner jarak antara elektroda arus dan elektroda potensial adalah sama. Seperti yang tertera pada Gambar 1.

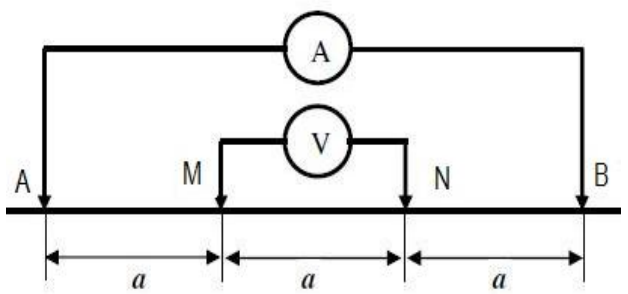

Gambar 1. Elektroda arus dan potensial pada konfigurasi Wenner.

Konfigurasi Wenner merupakan konfigurasi yang sering digunakan dalam eksplorasi geolistrik dengan susunan jarak spasi sama panjang ( $\mathrm{AM}=$ $\mathrm{NB}=\mathrm{a}$ dan $\mathrm{MB}=\mathrm{AN}=2 \mathrm{a})$. Jarak antara elektroda arus adalah tiga kali jarak elektroda potensial, jarak potensial dengan titik souding-nya adalah a/2, maka jarak masing - masing elektroda arus dengan titik sounding-nya adalah $3 \mathrm{a} / 2$. Target kedalaman yang mampu dicapai pada metode ini adalah a/2. Dalam akuisisi data lapangan susunan elektroda arus dan potensial diletakkan simetri dengan titik sounding [2].

\subsection{Uji Pompa}

Dalam tahapan uji pemompaan (pumping test) pertama-tama yang harus dipahami adalah jenis auifer yang akan diuji. Dengan memahami jenis aquifer tersebut, maka dapat digunakan metode yang akurat dalam tahapan pumping test. Uji pompa yang dapat diambil adalah debit optimum bukan maksimum, hal ini bertujuan untuk menjaga kelestarian air tanah. Analisis uji pompa bertujuan untuk mengetahui kemampuan sumur bor dalam memproduksi air tanah dan juga mengetahui lapisan aquifer [3].

\subsection{Uji Kualitas Air}

Persyaratan kualitas menggambarkan mutu atau kualitas dari baku air bersih. Persyaratan tersebut hanya meliputi persyaratan kimia berdasarkan Ketentuan Peraturan Gubernur Bali No.8 tahun 2007 tentang Ambang Baku Mutu Air.

\section{METODE PENELITIAN}

\subsection{Tempat dan Waktu Penelitian}

Pengambilan data geolistrik dan uji pumping dilakukan di jalan Tunjung I, Denpasar Barat. Uji kualitas air dilakukan di Labolatorium
Analitik, Universitas Udayana, Bukit Jimbaran, Bali.

\subsection{Alat Penelitian}

Peralatan yang digunakan untuk melakukan penelitian antara lain Resistivity meter model SkillPro, Elektroda, Kabel penghubung, Aki, Laptop/computer, Software Res2dinv, Meteran dan penggaris, Alat tulis, Pipa, Bak penampungan, Stopwatch, Dip Meter.

\subsection{Alur Penelitian}

Diagram alir dalam pengolahan dan analisis data sebagai berikut:

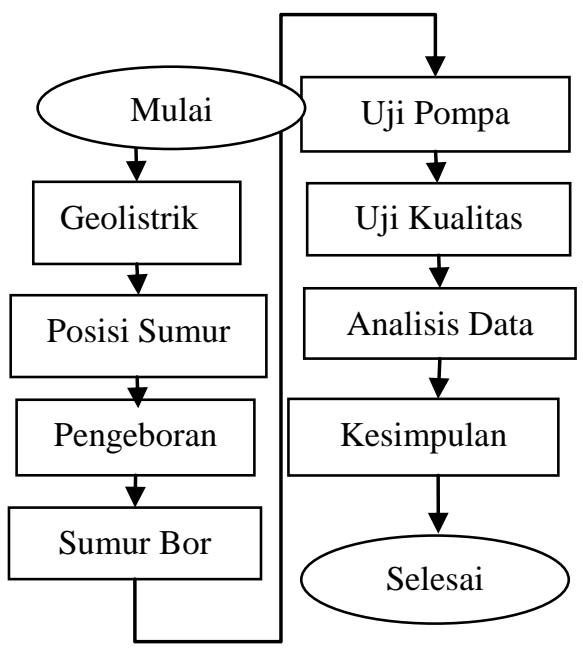

Gambar 2. Diagram alur penelitian.

\section{HASIL DAN PEMBAHASAN}

\subsection{Penelitian Menggunakan Geolistrik}

Berikut merupakan hasil dari pengambilan data geolistrik yang sudah diolah dengan Software Res2dinv untuk Konfigurasi Wenner:

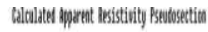

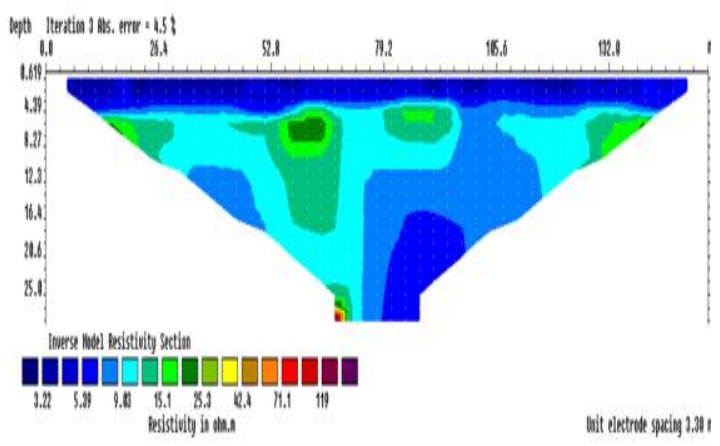

Gambar 3. Penampang Kontur Resistivitas Hasil Penelitian. 
Panjang lintas pengukuran adalah 155,1 m dengan jarak spasi antar elektroda sebesar 3,30 m. Koordinat titik nol meter terletak pada $8^{\circ} 33^{\prime} 43,76^{\prime \prime}$ LS dan $115^{\circ} 21^{\prime} 00,06^{\prime \prime}$ BT. Titik 155,1 m berada pada koordinat $8^{\circ} 33^{\prime} 44,90^{\prime \prime}$ LS dan $115^{\circ} 20^{\prime} 59,97^{\prime \prime}$ BT. Dari Gambar 3. dapat dilihat bahwa lapisan air permukaan terletak sampai kedalaman 5m. Air berasal dari permukaan meresap karena lokasi pengambilan data di areal persawahan.Berdasarkan Gambar 3 didapatkan bahwa aquifer baik terletak pada posisi $72,60-115,5 \mathrm{~m}$ dengan nilai resistivitas $3,22-5,39 \quad \Omega m \quad$ yang diinterpretasikan warna biru. Akumulasi air terbaik pada aquifer terletak pada posisi 79,2 - $99 \mathrm{~m}$ dan kedalaman 16,25-30 m yang diinterpretasikan dengan warna biru tua. Pada posisi inilah sebaiknya pengeboran dilakukan.

\subsection{Uji Pompa atau Pumping Test}

Hasil uji pumping selengkapnya dapat dilihat pada Tabel 1.

Berdasarkan Tabel 1 setiap pengaturan debit tertentu dilakukan tiga tahap pengukuran penurunan permukaan air di dalam sumur uji. Pengukuran penurunan kedalaman permukaan air dilakukan setiap 30 menit. Dimulai dari pukul 14.00 - 20.00 dengan waktu pompa selama 2 jam setiap satu tahap pengaturan debit sumur. Waktu total yang dibutuhkan uji pompa adalah 6 jam. Dengan kedalaman awal permukaan air dalam sumur 2 sebelum dilakukan uji pompa adalah $16,25 \mathrm{~m}$.

Berdasarkan Tabel 1 dapat dicari besarnya Konduktivitas hidraulik sumur (K), Transmisivitas (T), Storativitas (S) dan Spesifik Storativitas (Ss). Konduktivitas hidraulika sumur $2(\mathrm{~K})$ dapat dicari dengan rumus berikut:

$$
\mathrm{K}=\frac{Q}{F \Delta h}
$$

Dimana:

$$
\begin{aligned}
& \mathrm{K}=\text { Konduktivitas Hidraulik sumur } \\
& \begin{aligned}
(\delta \mathrm{r}) & =\text { jari-jari dalam casing sumur }(0,063 \mathrm{~m}) \\
\mathrm{F} & =\text { Konstanta sumur }(2,75)(\delta \mathrm{r}) \\
& =2,75 \times 0,063 \\
& =0,17325 \mathrm{~m}
\end{aligned}
\end{aligned}
$$

$\Delta \mathrm{h}=$ Penurunan permukaan air sumur $(\mathrm{m})$

Tabel 1. Tabulasi hasil uji pompa atau pumping test.

\begin{tabular}{cccc}
\hline $\begin{array}{c}\text { Debit } \\
\text { (L/Menit) }\end{array}$ & Waktu & $\begin{array}{c}\text { Kedalaman } \\
\text { sumur } \\
\text { pantau (M) }\end{array}$ & $\begin{array}{c}\text { Kedalaman } \\
\text { sumur } \\
\text { geolistrik (M) }\end{array}$ \\
\hline 0 & - & 15,25 & 16,25 \\
& 2 jam & 15,25 & 17,50 \\
13,63 & 2 jam & 15,25 & 17,75 \\
& 2 jam & 15,25 & 17,80 \\
& 2 jam & 15,25 & $17,80^{*}$ \\
& 2 jam & 15,25 & 19,25 \\
32,00 & 2 jam & 15,25 & 19,40 \\
& 2 jam & 15,25 & 19,50 \\
& 2 jam & 15,25 & $19,50{ }^{*}$ \\
& 2 jam & 15,25 & 27,42 \\
94,00 & 2 jam & 15,25 & 27,57 \\
& 2 jam & 15,25 & 27,65 \\
& 2 jam & 15,25 & $27,65^{*}$ \\
\hline
\end{tabular}

*untuk menguji data diatasnya

Nilai $\mathrm{K}_{1}$ menjadi:

$$
\begin{aligned}
& K 1=\frac{13,63 \text { l } / \text { menit }}{0,17325 \text { mx } 1,55 m} \\
& =0,84594021 \times 10^{-3} \mathrm{~m} / \mathrm{s} \\
& =0,8459402 \times 10^{-3} \mathrm{~m} / \mathrm{s}
\end{aligned}
$$

Dengan cara yang sama didapat nilai $\mathrm{K}_{2}$ dan $\mathrm{K}_{3}$ :

$\mathrm{K}_{2}=1,810824 \times 10^{-3} \mathrm{~m} / \mathrm{s}$

$\mathrm{K}_{3}=0,7442657 \times 10^{-3} \mathrm{~m} / \mathrm{s}$

Jadi nilai K adalah $0,1133677 \times 10^{-2} \mathrm{~m} / \mathrm{s}$

Selanjutnya untuk mencari nilai Transmisivitas (T) adalah dengan rumus berikut:

$$
T=K b
$$

dengan nilai $\mathrm{Kol}$ iur sebesar $0,001133677 \mathrm{~m} / \mathrm{s}$ dan nilai $\mathrm{b}$ adalah ketebalan aquifer sebesar $13,75 \mathrm{~m}$.

$\mathrm{T}=0,001133677 \mathrm{~m} / \mathrm{s} \times 13,75 \mathrm{~m}$

Jadi nilai Transmisivitas adalah sebesar

$0,1558808 \times 10^{-1} \mathrm{~m}^{2} / \mathrm{s}$.

Nilai Spesifik Storativitas (Ss) dapat dicari dengan rumus berikut:

$$
S s=\rho g(\alpha+\phi \beta)
$$

Dimana: 
Ss $=$ Spesifik Storativitas

$\rho=$ Kerapatan Air $\left(1000 \mathrm{~kg} / \mathrm{m}^{3}\right)$

$\mathrm{g}=\operatorname{Gravitasi}\left(9,72 \mathrm{~m} / \mathrm{s}^{2}\right)$

$\Phi=$ Porositas pasir $(35 \%)$

$\beta=$ Kompresibilitas $\left(4,4 \times 10^{-3} \mathrm{~ms}^{2} / \mathrm{kg}\right)$

$\alpha=$ Kompresibilitas aquifer $\left(10^{-8} \mathrm{~m}^{2} / \mathrm{N}\right)$

Ss $=1000 \mathrm{~kg} / \mathrm{m}^{2} \cdot 9,72 \mathrm{~m} / \mathrm{s}^{2}\left(10^{-8} \mathrm{~ms}^{2} / \mathrm{kg}+\right.$ $35 \% .4,4 \times 10^{-8} \mathrm{~ms}^{2} / \mathrm{kg}$ )

$=0,9869 \times 10^{-4} / \mathrm{m}$

Nilai $\mathrm{S}$ dapat dicari dengan rumus berikut :

$$
S=S s x b
$$

dengan $b$ ketebalan aquifer(13,75 m)

$$
\begin{aligned}
& \mathrm{S}=0,9869 \times 10^{-4} / \mathrm{m} \times 13,75 \mathrm{~m} \\
& =13,5698 \times 10^{-4} \\
& =0,1356 \times 10^{-2}
\end{aligned}
$$

Berdasarkan parameter aquifer yang didapat, diinterpretasikan bahwa: konduktivitas hidrolik $0,113377 \times 10^{-2} \mathrm{~m} / \mathrm{s}$, menurut Todd (1980) aquifer berupa pasir, Transmisivitas $0,1558808 \quad x \quad 10^{-1} \quad \mathrm{~m}^{2} / \mathrm{s}$, menurut U.S Def. of the Interior (2012) produktivitas sumurnya sangat baik untuk keperluan domestic dan irigasi, Storativitas $0,1356 \times 10^{-2}$, menurut Todd (1980) aquifernya merupakan aquifer tertekan. Hasil pendugaan juga dibuktikan dengan hasil pengeboran yaitu pada daerah aquifer berupa pasir. Hasil pengukuran geolistrik menunjukan di sekitar aquifer ada perlapisan dengan resistivitas lebih tinggi yang berarti aquifernya berupa auifer tertekan.

\subsection{Uji Kualitas Air Sumur}

Data pada Tabel 2 merupakan hasil uji kualitas air yang dikeluarkan oleh pihak Laboratorium Analitik, universitas Udayana.

Berdasarkan Tabel 2 dapat diketahui bahwa air dari sumur geolistrik memiliki kualitas yang lebih baik dari sumur 1, karena nilai parameter kualitas air untuk sumur geolistrik sudah sesuai dengan ketentuan

\begin{tabular}{|c|c|c|c|c|}
\hline \multirow[t]{2}{*}{ No } & \multirow{2}{*}{$\begin{array}{l}\text { Para- } \\
\text { meter }\end{array}$} & \multicolumn{2}{|l|}{ Hasil } & \multirow{2}{*}{$\begin{array}{l}\text { Amba- } \\
\text { ng }\end{array}$} \\
\hline & & Air S1 & Air S2 & \\
\hline 1 & $\mathrm{pH}$ & 7,17 & 7,47 & $6-9^{1}$ \\
\hline 2 & $\mathrm{COD}$ & $24,099^{*}$ & 9,205 & $10^{1}$ \\
\hline 3 & BOD & $11,315^{*}$ & 4,733 & $10^{1}$ \\
\hline 4 & NO2 & 0,036 & Ttd & $0,06^{1}$ \\
\hline 5 & NO3 & $\mathrm{Ttd}$ & Ttd & $10^{1}$ \\
\hline 6 & $\mathrm{SO} 4$ & 63,468 & 12,165 & $100^{1}$ \\
\hline 7 & $\mathrm{Cl}$ & 24,85 & 21,30 & $600^{1}$ \\
\hline 8 & NH3 & 0,385 & $\mathrm{ttd}$ & $0,50^{1}$ \\
\hline
\end{tabular}
Peraturan Gubernur Bali No.8 Tahun 2007 dalam batas ambang yang sudah ditentukan.
Tabel 2. Hasil Uji Kualitas Air Sumur.

\section{KESIMPULAN}

Adapun kesimpulan dari hasil penelitian yaitu:

1. Aquifer yang baik terletak pada kedalaman 16,25 meter dengan nilai resistivitas $3,22 \Omega \mathrm{m}$. Hasil pengolahan Uji pumping menunjukan nilai konduktivitas hidrolik $1,13377 \times 10^{-3} \mathrm{~m} / \mathrm{s}$ dengan aquifer berupa pasir. Transmisivitas $0,1558806 \quad x \quad 10^{-1}$ $\mathrm{m}^{2} / \mathrm{s}$ dengan produktivitas sumurnya sangat baik untuk keperluan domestic dan irigasi. Storativitas $0,1356 \times 10^{-2}$ yang berarti aquifernya merupakan aquifer tertekan [5].

2. Berdasarkan hasil uji kualitas di laboratorium, air sumur 2 memiliki kualitas yang lebih baik dari sumur 1. Air sumur 2 sudah sesuai ambang batas yang ditentukan dan air sumur 1 memiliki 2 nilai parameter diatas ambang batas yang sudah ditentukan.

\section{DAFTAR PUSTAKA}

[1] Adhi, M. 2003. Metode Geofisika. Semarang: Universitas Negeri Semarang.

[2] Bisri, m. 2012. Pengantar Ilmu Lingkungan. Jakarta: Mutiara Sumber Widya.

[3] Redana, I W. 2012. Air Tanah. Denpasar: Udayana University Press.

[4] Peraturan Gubernur Bali No. 8 Tahun 2007 Tentang Baku Mutu Lingkungan dan Baku Mutu Kerusakan Lingkungan Hidup.

[5] Todd, D.K. 1980. Groundwater Technology. New York: John. 